\title{
VEEL ÜHEST KANNIKESESINISEST
}

\author{
MEELI SEDRIK
}

Annotatsioon. Lääne-Eestis on eeskätt sinise ja lilla värvitooni ühe murdenimetusena kirja pandud tüvi panksee $\sim$ pankse $(-) \sim$ panksi(-) $\sim$ pank- $\sim$ ponks( $i)-$. Sellist värvitooni saadi kodus lõnga, riiet vm poevärviga värvides. Tüvi on eesti murretesse laenatud. Võimaliku laenuallika leiab saksa ja rootsi keelest, saksa Pensee, rootsi pensé 'aedkannike, võõrasema', mõlemas keeles saab sama sõnaga nimetada ka lille õite iseloomulikku värvi. Tõenäolisem laenuallikas on saksa keel, eesti murretes on teisigi saksa laenudest värvisõnu.

Võtmesõnad: eesti murded, keelekontaktid, leksikoloogia, etümoloogia, laensõnad

\section{Sissejuhatuseks}

Lääne-Eestist on ühe sinise ja lilla värvitooni nimetusena eesti murrete üldsõnavara kartoteegis kirja pandud pankse(e) ja panksi ning pankse-, panksi-ja panksinine (Eesti Keele Instituudi eesti murrete ja sugulaskeelte arhiiv, EMSUKA). Hiiumaalt leiab nende kõrvale esisilbi o-ga ponks(i)sinise ja lisaks veel variandid punksisinine ja prönkssinine. Teateid on saarte murdest Hiiumaalt kõikidest kihelkondadest ja Muhust ning läänemurde alalt Lääne-Nigula, Vigala, Kirbla, Karuse, Hanila, Varbla, Mihkli, Tõstamaa ja Pärnu-Jaagupi kihelkonnast, lisaks ka läänemurde naabrusest Risti kihelkonnast. Järgmisena esitan variantide ja kasutuse kohta näiteid eesti murrete üldsõnavara kartoteegist (lihtsamas, eesti murrete sõnaraamatus kasutatud transkriptsioonis, vt EMS I: 29-32). Ühest kihelkonnast pärit näited on kogutud eri keelejuhtidelt.

Muh panksee sinine 'teat. tumesinine värv'. panksee sinine värm oo `sõuke tume põle `sõuke ere sinine mitte

Emm ponks sinine 'lillakas sinine'. Ponks sinisel kut oleks 'kulda seas olad

Emm ponksi sinine on sinililla 
Emm panksi sinine $=$ prönks sinine $($ teat. tumesinine poevärv)

Käi Poest osteti veel kahesugust sinist [värvi]: tumedamat punksisinist ja heledamat leinpuusinist

Käi ponksi sinine 'teat. poest toodav sinine värv'. ponksi sinine 'toodi 'poodist. äi nüit pole seda änam

Käi Ponkssinine 'lilla' ja neiblasinine 'helesinine', olid ostetud värvist

Käi ponkssinine 'lilla' [küütkuue värv]

Rei ponks sinine 'lillakassinine'

$\mathrm{Phl}$ ponksisinine 'teat. sinine värv'. ponksi sinine pole ta hele, pole ta tume kaa

\section{LNg panksinine}

Vig 'panksi sinine 'ilus tumesinine' (poevärv)

Vig panksisinine panksi 'ultramariin'. üksvahe oli ’panksisinist, värmiti sukki ja 'lõnga. panksi oli `veltse värm. panksi sinine - vaśk `katla sees värmitti, 'lahtiselt müiässe sedä, tärä ja `väikse natukse kaupa, loe `viisi, kuda 'keegi tahtis võtta. panksi ja lellaga sai lenast `värmi - aga läks peält ää, ei seisnd. mool oo neid vanaaeksid 'kot'ta koa sii, saa arugi, kas oo värmitud või põlegi. panksi oo `veltse värm, 'soola pandi sesse, sis seesäb änäm pëäl, ei leekidä ää

Kir pankse. kui sa `tahtsid `mitmed 'värvi [lõnga] siis sèo siit linadega .. 'kinni. siis see tups värvi iśi 'värvi, kas kollast või rohelest. ja siis see teene tups sèo siit vahelt ’älle `kinni, see tee siis niukses pankses. (kuidas?) pankse, pankse

Kse 'panksi sinine 'mingi poe värv'. 'panksi sinine oo üks teras värm. arjuskid ja venelased tõid

Kse 'panksisinine oo lillakas; 'panksisinine oo tume sinine ‘riide värm

Han panksee. 'lilla värvus'. panksee põhaga seelikud olid vanaste kangeste 'moodis

Han panksee. 'lillakassinine värvus' van. 'panksee. 'värvi osteti puest

Han panksisinine 'värv, lillakas sinine?'

Var panksinine oo isemoodi sinine, lillakas sinine

Mih 'panksesinine 'lilla'

Tõs ’panksi värm oo sinikas lilla; ’panksi värmiga värviti 'lõngu ja körtä; 'panksi sinist osteti linnast puest hrl 
Tõs 'panksi sinine taevas; ’panksisinine läheb õege ruttu ää; 'panksisinine oo erk hrl

Tõs panksinine 'tume lillakassinine'. kiudu 'körtide 'aegas olid poevärvid. üks 'üiti panksinine. see oli naa lillakas sinine, tume oli

Tõs panksinine 'lillakassinine'. panksinine - tä oli, kui sa ete vähä panid, siis tuli roosa, ele roosa. aga kui 'rohkem panid, siis tuli tumedam sinine, aga roosa käib ikke üle

Tõs panksinine 'lillakassinine'. panksinist sai poest. olid lillakad sinised tükid, neid keedeti ja värviti, kui taheti teha vahel 'kanga lốimi ja

PJg panksinine ... rukkilille sinine 'mingi poevärv'

Ris 'panksee 'teat. endine sinine värv'

Ris 'pankse sinine, täis elgass, ilus sinine

Eraldi on kartoteegis paigutatud Kihelkonnalt pärit teade, mis on märgitud kui murrete sõnaraamatu käsikirjast välja jäetud sedel.

Khk ponks g. ponksi 'poe-värv, mis olnuvat plekk-karpides müügil' ponks = lekk-kaŕp, ponksi kaŕp ('kompvekikarp') vär'v sihes, se o ponksi värv

Nimetus on kirja pandud ka Andrus Saareste mõistelises sõnaraamatus: panksesinine 'violetne' (Mihkli) peatükis „Lilla” ja ponksisinine '?' (PõhjaPärnumaa) peatükis „Sinine” (EKMS 2: 584, 3: 847).

Murdenäidete valikust on näha, et seletusena on pakutud sinise toone (tumesinist, lillakassinist, ultramariini), lillat ja ka roosat. Vilja Oja (1997: 14) on varem kokku võtnud, et selle tüvega väljendatud sinist on kirjeldatud roosast tumesiniseni, olenevalt värvaine kontsentratsioonist saadakse mitmesuguseid toone, mis võivad kanda sama nimetust. Sinise värvi nimetust kasutatakse lilla kohta eesti keeles ja ka teistes läänemeresoome keeltes (Oja 2011a: 156).

Kõnealune värvinimetus on seni veel konkreetse etümoloogiata. Vilja Oja (1997: 14) on märkinud, et spetsiifilist värvitooni kirjeldavad nimetused lähtuvad substantiivist, mis viitab värvainele või selle päritolule, selle seisukoha näitena on madarase, hiina sinise, purpuri, košenill- ehk koosenipunase, potisinise ja -rohelise ning liinaka kõrval esitatud ka panksee 'tumesinine' (konkreetset allikat ei ole nimetatud). Kümmekond aastat hiljem on V. Oja (2007: 205) kirjutanud värvinimetuste variantide 
kohta, et aja möödudes võib sõna päritolu kasutajate jaoks hämarduda ja primaarseks saab omadussõnaline (värvuse) tähendus. Selle näitena on esitatud pronksi- ponksi- panklsinine, mille juures seletusvõimalustena nimetatud sõnad pronks '(metall)', ponks 'kompvek' ja pank 'tükk, kamakas'. Sinise ja punase segatooni jaoks on V. Oja andmetel (2011: 167) eesti ja soome murretes laennimetused, aga kasutatakse ka sinise ja punase nimetusi ning liitsõnu.

Ants Viires märgib eestlaste värvimaailma analüüsides, et sinise varjundite eristamiseks polnud meie esivanematel kaua vajadust, neid tähistatakse seniajani peamiselt liitsõnadega ning alles XIX-XX sajandil saadi eesti keelde saksa keele eeskujul lilla ja violett. Sinise saamiseks ei andnud kohalikud taimed püsivaid värvusi, hiliste värvinimetuste kasutusele võtmise aluseks oli odavate vabrikuvärvide laialdane levimine rahva hulgas. (Viires 1983: 298-299)

Murdenäidetest tuleb välja, et kõnealuse tüvega (panksee, pankse(-), panksi(-), pank-, ponks(i)-) nimetatud sinist või lillat tooni saadi (poest) ostetud värviga, st ajal, mil olid levima hakanud vabrikuvärvid. Uuemale laenule viitab ka ühe variandi, panksee rõhuline teine silp. Võimaliku laenuallika võib leida rootsi ja saksa keelest.

\section{Rootsi keeles}

Rootsi keeles on sõna pensé [pạse:], mis on Rootsi Akadeemia sõnaraamatu (SAOB) järgi kirja pandud ka kujul pangse. Sõnal on kaks tähendust: 1) 'tanke .. [mõte]', 2) 'växten Viola tricolor Lin., styvmorsviol; numera nästan bl. dels om (blomma av) den odlade, storblommiga, gm korsning av flera arter av släktet Viola Lin. uppkomna trädgårdsviolen Viola wittrockiana Gams (Viola tricolor Lin. f. maxima Hort.), dels /../ om (blomma av) den odlade, ur hybrider till Viola cornuta Lin. uppkomna, i olika former uppträdande, fleråriga växten Viola Williamsii Wittr. [aedkannike, võõrasema; praegu peaaegu ainult suureõieline kultuurtaim, perekonna Viola Lin. liikide ristamise teel saadud aedkannike Viola wittrockiana Gams ja kultuurtaime Viola cornuta Lin. hübriididest saadud mitmeaastane Viola Williamsii Wittr.]'. Teise tähenduse all on nimetatud, et sõna kasutatakse ka värvuse iseloomustamiseks: „om den i rödbrunt (1. blått) skiftande violetta färg som är utmärkande för många penséer" [punakaspruuni (v sinise) vahelduva violetse värvuse kohta, mis on iseloomulik paljudele 
aedkannikestele, võõrasemadele]. Samas sõnaartiklis on nimetatud nt liitsõnad pensébrun [aedkannikese-, võõrasemapruun], penséfärgad [aedkannikese, võõrasema värvi] ja pensésammet [aedkannikese, võõrasema värvi samet]. „Nationalencyklopedins ordbok” (NEOB: 569) annab lille tähenduse esmaesinemuseks 1802. aasta.

SAOB-s ja Elof Hellquisti (1922: 570) rootsi keele etümoloogilises sõnaraamatus on sõna märgitud prantsuse laenuks ( $<$ pr pensée). Rootsi (ja ka prantsuse) keele tähendused on omavahel seotud, kannike on rootsi keele etümoloogilise sõnaraamatu järgi meenutuseks antud lill (Hellquist 1922: 570). Prantsuse Akadeemia sõnaraamatus (DAF: 389) on aedkannikest, võõrasema tähistava märksõna pensée all esitatud väljend couleur de pensée, couleur pensée 'certain violet brun, tel que celui der fleurs de pensée [teatav pruunikaslilla, mis on iseloomulik aedkannikese, võõrasema õitele]'. Prantsuse keeles on kasutatud ka väljendit bleu de pensée 'bleu violet, bleu pourpre [lillakassinine, purpursinine]' (Jones 2013: 2038).

Sõna pensé on taime tähenduses antud ka uuemates rootsi keele sõnaraamatutes, nt Rootsi Akadeemia sõnastikus (SAOL: 679) tähendusega 'växt [taim]' ning Norstedtsi kirjastuse 1996. aastal välja antud suures rootsi keele sõnaraamatus (SSOB: 901) seletusega 'en odlad växt av violsläktet [kultuurtaim kannikese perekonnast]'. Rootsi-eesti sõnaraamatus (RES: 761) on esitatud pensé 'aedkannike, võõrasema' märgendiga „kõnekeelne”. Eraldi värvuse tähendust ei ole nimetatud sõnaraamatutes antud.

Rootsi keeles ei näi sõna värvuse tähenduses olevat väga levinud. Uusi värvisõnu XIX-XX sajandi rootsi keeles on uuritud Rootsi Akadeemia sõnaraamatu (SAOB) ja "Nationalencyklopedins ordbok'i” (NEOB) põhjal (Lange 2002), ainestiku põhiosa moodustavad sellised liitsõnalised nimetused, milles on ühe osisena põhivärvinimetused. Sellest materjalikogust tuleb välja ka SAOB-s olev pensébrun ['aedkannikese-, võõrasemapruun'] (Lange 2002: 22, 43). Interneti abiga leidsin ühe ilukirjandusnäite, kus on looduskirjelduses moodustatud liitsõna sinisega (Angered Strandberg 1905: 24).

Då dagen lider blir det till detta djupt penséblå mot gammalt guld, bekant från gamla mästares taflor.

[Päeva edenedes muutub see sügavaks kannikesesiniseks vanakuldsel taustal, tuntud vanade meistrite maalidelt.] 
Margareta Westman (1995: 120-124) on analüüsinud rootsi värvinimetuste lila, violett ja gredelint tähendusnüansse ja kasutust, lähedase tähendusega sõna pensé ta oma kirjatöös ei nimeta. Sellegi põhjal võib arvata, et praeguses rootsi kirjakeeles sõna aktiivselt ei kasutata.

\section{Saksa keeles}

Teise võimaliku laenuallikana tuleb kõne alla saksa keel. Saksa keeles on kasutusel sama prantsuse keelest laenatud tüvi Pensee, pensee. Saksa värvinimetuste leksikoni järgi on prantsuse keeles selle sõnaga tähistatud värvitooni juba näiteks 1667. a ilmunud raamatus ja varsti pärast seda, aastast 1683 on teada prantsuse sõna kasutamine juba saksakeelses (tõlke-) tekstis (Jones 2013: 2038).

Grimmide sõnaraamatust (DWB) sõna saksa vastet ei leia. Küll on sõna olemas Johann Georg Krünitzi (1773-1858) entsüklopeedias: Pensée 'das dreyfarbige Veilchen, Viola tricolos Linn. [kolmevärviline kannike]'. Sõna on olemas Dudeni sõnaraamatutes: kuueköitelises suures saksa keele sõnaraamatus (DGWB 5: 1968) pensee 'von dunklem Lila [tumedam lilla]', Pensee 'Bezeichnung für Gartenstiefmütterchen [aedkannike, võõrasema]', penseefarbig ['võõrasema värvi']; üheköitelises universaalsõnaraamatus (DUWB: 1133) pensee 'dunkelviolett [tumelilla]', Pensee 'Bezeichnung für Stiefmütterchen [aedkannike, võõrasema]' ja võõrsõnade sõnaraamatus (DFWB: 608) pensee 'dunkelviolett [tumelilla]', Pensee 'Bez. für: Stiefmütterchen [aedkannike, võõrasema]'. Saksa värvinimetuste leksikonis (Jones 2013: 2038) on antud omadussõna pensée 'violett' ja nimisõna Pensée 'violetter Ft. [violetne värvitoon]'. Saksa-eesti sõnaraamatusse (Kibbermann jt 2007) ei ole sõna võetud.

Nagu oli näha juba eesti murdematerjalis, on ka saksakeelsetes seletustes kirjeldatud värvitooni eri nüanssidega, sagedamini esineva lillavioletse kõrval on nt Eva von Hollanderi (1990: 303) võõrsõnade raamatus seletuseks antud ,rötlich braun, dunkellila [punakaspruun, tumelilla]”.

Saksa keele värvinimetuste leksikoni järgi (Jones 2013: 2038-2039) on saksa keeles kasutatud ka liitsõnu penséelila, Penseepurpur ja Penseeviolett.

Kõrvalepõikena võib nimetada, et inglise keeles on võõrasemaga võrreldud rohkemgi värve, lilla varjundeid tähistavate nimetuste pansée pansy, pansy-maroon, pansy purple, pansy violet kõrval on lillele iseloomuliku rohelise ja kollase kohta nimetused pancy green, pansy yellow (DCN). 


\section{Häälikuline muganemine}

Kõige lähedasem laenuallikale on eesti murrete variant panksee. Eesti keelele omaselt on sõnarõhk muganemisel liikunud esimesele silbile: pankse(sinine), panksi(sinine), ponksisinine. Saksa ja rootsi keeles on säilitatud prantsuse keele esimese silbi ortograafia, -en-(v.a üks kirjapanek SAOB-s, pangse, 1892. a), sellele on sõnaraamatutes lisatud hääldus: rootsi [paךse:] (SAOL; NEOB: 569), saksa [pã'se:] (DGWB 5: 1968, DFWB: 608; DUWB: 1133) ja ka [pañßê] (Hollander 1990: 303). Eesti keeles on uuemates laensõnades $n s$-ühendisse lisatud klusiil, selliseid näiteid on leida Ferdinand Johann Wiedemanni sõnaraamatust (1973:

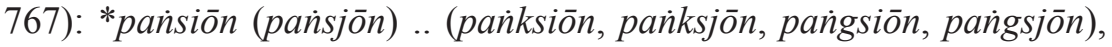
*panssionär (paingsjonär) [vrd *pensiōn (Wiedemann 1973: 800)].

Kui läänemurdes, Muhus ja Risti kihelkonnas on laenamisel $a$ säilinud, siis Hiiumaalt on kirjapanekud enamasti (ühe erandiga) o-ga. Paul Ariste (1939: 19) on oma doktoritöös nimetanud, et Hiiumaal võib labialiseeritud $a$ olla isikuti kas peaaegu või täiesti $o$, labiaalsus on üldisem ja tugevam just vanemate kõnelejate puhul. Lisaks on Hiiu murretes sõnu, milles $a$ ja $o$ vahelduvad, näiteks pastivahe 'postivahe' ja kajandus $\sim$ kojandu 'asterik aiast üleminekuks'; sellist segunemist on võimaldanud samuti labialiseeritud $a$ (Ariste 1939: 33).

Võib ainult oletada, kas ja kui palju on hääldust mõjutanud rahvaetümoloogia võimalus, mida saab aimata Kihelkonna teatest: ponks kui poevärv, mida müüdi plekk-karpides ehk ponksi-, kompvekikarpides. See on olnud arvatavasti üks viis muuta võõrast sõna enda jaoks arusaadavamaks.

Järgsilbis on $e$ sageli asendunud $i$-ga (panksi-, ponksi-) või on $e / i$ hoopiski kadunud (ponks(sinine)). Läänemurdes Lääne-Nigulas, Varblas, Tõstamaal ja Pärnu-Jaagupis on täiendsõna veelgi lühenenud ja alles on jäänud pank(sinine). Hiiumaal kirja pandud variandid punksisinine ja prönkssinine on tõenäoliselt juhuslikumad. Ka teistele laenatud värvinimetustele (nagu üldse laensõnadele) on murretes iseloomulik variantide rohkus, vrd oranž värvaine, nn orlean (vrd saksa Orlean(s)) ja mugandatud variandid 'ordjan, 'ordjon, 'ordjom, ordijuan, ordijuuń, ordejaań, oŕt, liitnimetustes ka `ordeni-, ’ordani-, ordjani-jt (Oja 2001: 29; 2011b: 138) ning neiblu-, neiblasinine, neibu, neinpuu, leinpuusinine (vrd saksa Neublau) (Oja 2001: 29). Kindlasti on soodustanud variantide tekkimist värvisõnale liidetud täiendsõna ähmaseks jäänud tähendus. 


\section{Tähendus}

Värvitoonide nimetamine taimede ja taimeosade järgi on väga levinud (saksa keele näiteid vt nt Oksaar 1988: 15, rootsi keele näiteid Lange 2002: 22). Kannikese ja sinililla värvitooni kõrvutusega leiab eesti keeleski moodustusviisilt analoogilisi nimetusi: kirjakeeles kannikesesinine, eesti murretes viiulisinine, viiulde sinine (Oja 2011b: 126, 134), vrd saksa Viol(en)blau 'kannikesesinine', Viole 'lõhnav kevadlill (Viola martis, Viola odorata)', Violettblau (DWB), rootsi violblå 'kannikesesinine', viol 'kannike' (SAOB: blå). Kirjakeelne violett on laenatud saksa keelest (< saksa Violette 'kannike', violett 'violetne, kannikesevärvi'; EEW XII: 3870; DWB).

Teateid panksi-, ponksi-tüve või selle variantide kohta kannikese ja võõrasema nimetusena eesti murretes ei ole. Saksa- ja rootsikeelse sõna tähendustes nimetatud liigi Viola tricolor L. kohta on Gustav Vilbaste (1993: 666-667) märkinud, et sellel on kõige rohkem naaberkeeltest tõlgitud nimetusi ja nende moonutusi. Nende hulgas ega ka mitte teiste kannikeseliikide nimetuste hulgas saksa Pensee-, rootsi pensé-tüve mugandusi ei ole. Küll on aga saksa sõnade Stiefmütterchen 'aedkannike, võõrasema', Viole ja Veilchen 'kannike' mugandusi ja tõlkeid (vt Vilbaste 1993: 666-667).

Eesti murrete üldsõnavarakartoteegis (EMSUKA) ei ole värvitooni iseloomustamisel kordagi kannikest nimetatud, ühes teates on värvitooni kirjeldatud kui rukkilillesinist. Nii võib arvata, et värvitooni tähenduses on sõna saadud eesti murretesse koos poevärviga. See poevärv oli tõenäoliselt saadaval juba XIX sajandil, kui valmistati ja kanti triibulisi rahvariideseelikuid.

1900. aastal ilmunud Kristiane Frisacki raamatus on antud õpetusi kodus värvimiseks, kasutades nii taimi kui ka poest ostetavaid aineid, lisatud on värvitabel; eestikeelses tõlkes on sinise värvitooni iseloomustamiseks kasutusel tavapäraselt liitsõnad ja sõnaühendid: pottsinine, tumesinine, keskmine sinine, hele sinine, weekarwa sinikas, rohikas-sinine, sinikas-wiolet, tume rohikas-sinine, õige mustjas-sinine (Frisack 1900a: 38-42). Peatükis ,Wiolet värvid” on loetletud tume-punakas wiolet, punakas-wiolet, punane wiolet, sinikas-wiolet, pruunikas hall-wiolet (Frisack 1900a: 42-44). Moodustuselt analoogilised on nimetused ka sama raamatu saksakeelses tõlkes: Pottisini, Dunkelblau, Mittelblau, Hellblau, Wasserblau, Grünblau, Blau mit Übergang in's Violette, Dunkles Grünblau, Tiefes 
Dunkelblau, Dunkle Mittelfarbe in Grünblau ning Dunkles Rotviolett, Rotviolett, Blauviolett, unbestimmtes Braun-Grauviolett (Frisack 1900b: 40-46). Võib arvata, et värvinimetused panksi- ponksisinine jt jäid siiski teatud piirkonna rahvakeelde, nagu kinnitavad ka murdeandmed.

\section{Kas rootsi või saksa laen?}

Kas panksee, pankse(sinine), panksi(sinine), pank-, ponks(i)sinine on laenatud saksa või rootsi keelest? Häälikuliselt ja tähenduslikult sobivad laenuallikaks mõlemad keeled. Nii saksa kui ka rootsi keeles võib sõnaraamatute järgi kasutada taimenimetust värvuse tähenduses ilma värvisõna lisamata; eesti murretestki on üksikuid teateid, kus sõna panksee tähistab värvust ilma täpsustava värvisõnata.

Rootsi keeles on sõna taimenimetusena tänapäeval ilmselt tavalisem kui saksa keeles, kui arvestada, et see on võetud näiteks rootsi-eesti sõnaraamatusse (RES: 761). Tüve levik Lääne-Eestis on tüüpiline rootsi laenude leviala. Aga soome murretes, kus rootsi laene on ka värvinimetuste seas (nt (p)ruuni, liusi, kretliini, (k)rööni, vt Oja 2011a: 149, 154, 157, 165), ei ole rootsi pensé-tüvest saadud laenu nimetanud ei Vilja Oja (2011a) ega ka Mauno Koski (1983). Kui soome murretes ja kõnekeeles on lilla tähenduses tuntud rootsi laen kretliini koos oma variantidega (Oja 2011a: 157), siis selle võimaliku vaste kohta eesti murretes teateid ei ole.

Hiiumaal oli ponks(i)sinine kindel rahvariideseeliku ehk küüdu triibu värvus; Erna Ariste (ERM EA 18: 26, 305) on 1933. aastal keelejuhilt üles kirjutanud järgmised näited.

Küit-kuuel, nom. küit-kuub, oli punane päävärv. Pääle selle olid: liinepunane, roheline, ponkssinine, neilbåsinine, kollane, ehtmust. Päävärv oli kalevipunane. Liinepunane on violett, ponkssinine - lilla ja neilbåsinine - helesinine. Viimase ja varema aja küitkuubede värvides oli ainult toonivahesid.

Ponkssinine 'lilla' ja neiblasinine 'helesinine' olid ostetud värvist.

Hiiumaal võiks oodata sõnavaras rootsi mõjusid, aga näites esinevad värvinimetused on eesti murretes mujalgi tuntud. Nii neilbå-, neiblasinine kui ka liinepunane on laenatud nimetused.

Neibla-, neiblu-, neilbu-, neinpuu-, leinpuusinine jt on saadud saksa keelest (< saksa Neublau; Oja 2007: 205). Saksa värvinimetuste leksi- 
kon annab saksa Neublau tähendusteks 'Sächsischblau [Saksi sinine]; Waschblau, blaugefärbte Stärke [pesusine, siniseks värvitud tärklis]; Berliner Blau-Sorte oder -Verschnitt [Berliini sinine või siniste segu]; Meldolas Blau [Meldola sinine]; Indigoblau(lack) [indigosinine (lakk)]' (Jones 2013: 1959). Saksi sinise tähenduses leidub samas allikas näide ka 1781. aastal ilmunud sõnaraamatust: „Blautinktur, (Fårberey) eine blaue Farbe, womit man das sogenannte săchsische Blau oder Neublau fărbet. Sie ist vor einigen Jahren vom Herrn Barth in Großenhayn in Sachsen erfunden worden [aus Vitriol, Kobalt u. Indigo] [Sinine tinktuur, sinine värv, millega värvitakse nn Saksi sinist ehk uussinist. Selle on leiutanud mõne aasta eest härra Barth Großenhaynist Saksimaal [vitriolist, koobaltist ja indigost]" (Jones 2013: 1959).

Sõnade liina, liine puhul on variante rohkesti (vt nt Oja 2011b: 134-135; EMS V: 196-197), on arvatud, et nende lähtekohaks võib olla värvaine nimetus aniliin (Oja 2011a: 159-160; 2011b: 135) või vene мали́на 'vaarikas' (Must 2000: 191), on võimalik ka nimetatud kahe allika segunemine (Oja 2011b: 135). Aniliin kui üks oluline poevärvi koostisosa on nii saksa kui ka rootsi keeles värvinimetuste täiendosa: nt saksa Anilinfarben ['aniliinvärvid'] (DGWB 1: 141), Anilinrot ['aniliinpunane'] (BW: 232), rootsi anilinblå, -brun, -grå, -gul, -röd, -svart jt ['aniliinsinine, -pruun, -hall, -kollane, -punane, -must'] (SAOB).

Oranži värvaine järgi, mis on saksa keeles $\operatorname{Orlean}(s)$ ), on saadud eesti murrete variandid `ordjan, 'ordjon, 'ordjom, ordijuan, ort, liitnimetused 'ordeni(kollane) jt (Oja 2011b: 138). Saksa keeles on Orlean (Orleans) 'gelbes, aus der Umhüllung der Samenkörner des Rukubaumes (Bixa orellana) gewonnenes Fm. (enthält Bixin u. Orellin) [värvibiksa (Bixa orellana) puu seemnekestadest valmistatud kollane värvaine (sisaldab biksiini ja orelliini)]' (Jones 2013: 2009).

Selliste murretes tuntud värvinimetuste hulgas leiab saksa päritolu laene kindlasti veelgi.

Kas laenuandjakeel võib olla rootsi või saksa keel, peab otsustama tõenäoliselt keeleväliste tegurite järgi, selle järgi, kas poevärvid jõudsid Eestisse peamiselt Saksamaalt või Rootsist. Võib arvata, et kaubandussidemed Saksamaaga olid selles valdkonnas tihedamad, sellele viitavad ka teised saksa päritolu värvinimetused, nt nimetatud neiblasinine ning ordenikollane koos variantidega. 


\section{Kokkuvõtteks}

Värvinimetus panksee $\sim$ pankse (sinine) $\sim$ panksi(sinine $) \sim$ panksinine $\sim$ ponks $(i)$ sinine on tuntud Lääne-Eestis saarte ja läänemurdes, lisaks Risti kihelkonnas, ning tähistab eeskätt mitmesuguseid sinise ja lilla toone. Panksee, pankse(-), panksi(-), pank-, ponks(i)- on eesti murretes uuem laen. Laenuallikaks sobib saksa Pensee või rootsi pensé 'aedkannike, võõrasema', sama sõnaga tähistatakse mõlemas keeles ka lille õite iseloomulikku (lillat) värvust. Nimetus on laenatud tõenäoliselt koos poest ostetud värviga, sest taimenimetusena kasutamise kohta eesti murretes teateid ei ole. Tõenäolisem on laenamine saksa keelest, seda võib eelistada seepärast, et saksa keelest on laenatud teisigi uuemaid värvinimetusi.

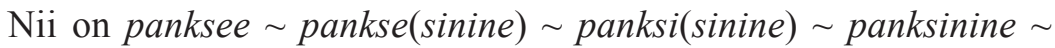
ponks(i)sinine eesti murretes veel üks kannikese õite järgi antud värvinimetus.

\section{Kirjandus}

Angered Strandberg, Hilma 1905. Under söderns sol. Stockholm: Wahlström \& Widstrands Förlag. http://runeberg.org/ashsoderns/ (04.01.2014).

Ariste, Paul 1939. Hiiu murrete häälikud. (= Acta et Commentationes Universitatis Tartuensis B XLVII,1. 1940.) Tartu.

BW = Brockhaus-Wahrig Deutsches Wörterbuch in sechs Bänden. I (A-Bt), 1980. Hrsg. von Gerhard Wahrig, Hildegard Krämer, Harald Zimmermann. Wiesbaden: F. A. Brockhaus, Stuttgart: Deutsche Verlags-Anstalt.

DAF $=$ Dictionnaire de l'Académie française. II (I-Z), 1879. Septième édition. Paris: Firmin-Didot.

DCN = ISCC-NBS Dictionary of Colo(u)r Names. 1955. http://tx4.us/nbs/nbs-p. htm (02.01.2014).

DFWB = Duden: Fremdwörterbuch. 1997. Hrsg. und bearb. vom Wissenschaftlichen Rat der Dudenredaktion. 6., auf der Grundlage der amtlichen Neuregelung der deutschen Rechtschreibung überarbeitete und erweiterte Auflage. Mannheim-Leipzig-Wien-Zürich: Dudenverlag.

DGWB 1 = Duden: Das große Wörterbuch der deutschen Sprache in sechs Bänden. 1 (A-Ci), 1977. Hrsg. und bearb. vom Wissenschaftlichen Rat und den Mitarbeitern der Dudenredaktion unter Leitung von Günther Drosdowski. Mannheim-Wien-Zürich: Bibliographisches Institut.

DGWB 5 = Duden: Das große Wörterbuch der deutschen Sprache in sechs Bänden. 5 (O-So), 1980. Hrsg. und bearb. vom Wissenschaftlichen Rat 
und den Mitarbeitern der Dudenredaktion unter Leitung von Günther

Drosdowski. Mannheim-Wien-Zürich: Bibliographisches Institut.

DUWB = Duden: Deutsches Universalwörterbuch. 1996. Bearb. von Günther

Drosdowski und der Dudenredaktion. 3., neu bearbeitete und erweiterte

Auflage. Mannheim-Leipzig-Wien-Zürich: Dudenverlag.

DWB $=$ Das Deutsche Wörterbuch von Jacob und Wilhelm Grimm auf CD-

ROM und im Internet. http://germazope.uni-trier.de/Projekte/DWB (02.01.2014).

EEW = Julius Mägiste 1982-1983. Estnisches etymologisches Wörterbuch. I-XII. Helsinki: Finnisch-Ugrische Gesellschaft.

EKMS = Andrus Saareste 1958-1963. Eesti keele mõisteline sõnaraamat. I-IV.

Dictionnaire analogique de la langue estonienne. Avec un index pourvu des traductions en français. (= Eesti Teadusliku Seltsi Rootsis väljaanne nr. 3.) Stockholm: Vaba Eesti.

EMS I = Eesti murrete sõnaraamat. I (A-J), 1994-1997. Trükki toim. Helmi Neetar, Ellen Niit, Eevi Ross. Eesti Teaduste Akadeemia. Eesti Keele Instituut.

EMS V = Eesti murrete sõnaraamat. V (L-M), 2009-2013. Toim. Mari-Liis Kalvik, Mari Kendla, Vilja Oja, Tiina Tärk, Jüri Viikberg. Eesti Teaduste Akadeemia. Eesti Keele Instituut. Tallinn: Eesti Keele Sihtasutus.

ERM EA 18 = Erna Ariste 1933. Etnograafilisi märkmeid Hiiumaalt, 11-480.

Frisack, Kristiane 1900a. Kristiane Frisack'i Norra wärwiraamat, ühes 100 wärviwalmistamise eeskirja ja üks wärwitabel. Tõlge. Wälja andnud Liiwimaa Selts naisterahwa töö edendamiseks. Jurjew (Tartu): H. Laakmann.

Frisack, Kristiane 1900b. Übersetzung des Norwegischen Färbebuches von Cristiane Frisack, enthaltend 100 Recepte und eine Farbentafel. Hrsg. vom „Livländischem Verein zur Förderung der Frauen-Arbeit”. Jurjew (Dorpat): H. Laakmann.

Hellquist, Elof 1922. Svensk etymologisk ordbok. Lund: C. W. K. Gleerups Förlag. http://runeberg.org/svetym/ (02.01.2014).

Hollander, Eva von 1990. Das tägliche Fremdwort. Hamburg: Xenos.

Jones, William Jervis 2013. Historisches Lexikon deutscher Farbbezeichnungen. IV, Frühneuhochdeutsch-Neuhochdeutsch, L-R. Berlin: Akademie Verlag. http://dx.doi.org/10.1524/9783050063225.

Kibbermann jt 2007 = Elisabeth Kibbermann, Salme Kirotar, Paula Koppel. Saksa-eesti sõnaraamat. Toim. ja täiend. Anne Arold, Mari Tarvas, MariAnn Palm. Valgus.

Koski, Mauno 1983. Värien nimitykset suomessa ja lähisukukielissä. (= Suomalaisen Kirjallisuuden Seuran toimituksia 391.) Savonlinna: Suomalaisen Kirjallisuuden Seura.

Krünitz, Johann Georg 1773-1858. Oeconomische Encyklopädie, oder allgemeines System der Staats- Stadt- Haus- und Landwirthschaft, in alphabetischer Ordnung. http://www.kruenitz1.uni-trier.de/ (02.01.2014). 
Lange, Sven 2002. Om nya färgord i svenskan under 1800- und 1900-talet. (= Rapporter från ORDAT. Det svenska ordförrådets utveckling 1800-2000.) Göteborg. http://spraakdata.gu.se/ordat/pdf/ORDAT16.pdf (04.01.2014).

Must, Mari 2000. Vene laensõnad eesti murretes. Tallinn: Eesti Keele Sihtasutus. NEOB $=$ Nationalencyklopedins ordbok. 1996. 1 [Hå-Reko]. Utarbetad vid Språkdata, Göteborgs universitet. Bokförlaget Bra Böcker.

Oja, Vilja 1997. Värvinimetuste moodustamine eesti murretes. Preprint. Eesti Teaduste Akadeemia. Eesti Keele Instituut. Tallinn: Teaduste Akadeemia. Eesti Keele Instituut.

Oja, Vilja 2001. Linguistic studies of Estonian colour terminology. (= Dissertationes philologiae Estonicae Universitatis Tartuensis 9.) Tartu University Press.

Oja, Vilja 2007. Colour naming in Estonian and cognate languages. Anthropology of Color. Interdisciplinary multilevel modeling. Ed. Robert E. MacLaury, Galina V. Paramei, Don Dedrick. Amsterdam, Philadelphia: John Benjamins, 189-209.

Oja, Vilja 2011a. Kromaatiliste värvide nimetustest läänemeresoome murretes. Värvinimede raamat. Koost. ja toim. Mari Uusküla, Urmas Sutrop. (= Töid antropoloogilise ja etnolingvistika vallast 5.) Tallinn: Eesti Keele Sihtasutus, 143-167.

Oja, Vilja 2011b. Põhivärvinimetuste vasted eesti murretes. - Värvinimede raamat. Koost. ja toim. Mari Uusküla, Urmas Sutrop. (= Töid antropoloogilise ja etnolingvistika vallast 5.) Tallinn: Eesti Keele Sihtasutus, 121-140.

Oksaar, Els 1988. Fachsprachliche Dimensionen. (= Forum für FachsprachenForschung 4.) Tübingen: Gunter Narr Verlag.

RES $=$ Rootsi-eesti sõnaraamat. Svensk-estnisk ordbok. 2004. Koostanud / utarbetad av Mari Aidla, Signe Cousins, Maiu Elken, Madis Kanarbik, Kristina Mullamaa, Tiina Mullamaa, Marina Pertšjonok, Mai Praizner, Raimo Raag, Virve Raag, Juhan Tuldava. Valgus.

SAOB $=$ Svenska Akademiens ordbok. http://g3.spraakdata.gu.se/saob/ (02.01.2014).

SAOL $=$ Svenska akademiens ordlista över svenska språket. 2006. Trettonde upplagan, tredje tryckningen. Stockholm: Norstedts Akademiska Förlag. http://www.svenskaakademien.se/svenska_spraket/svenska_akademiens_ordlista/saol_pa_natet/ordlista (02.01.2014).

SSOB $=$ Stora svenska ordboken. 1996. Utarbetad vid Språkdata, Göteborgs universitet. Norstedts.

Viires, Ants 1983. Eestlaste värvimaailm. - Keel ja Kirjandus 6, 290-302.

Vilbaste, Gustav 1993. Eesti taimenimetused. Nomina vernacula plantarum Estoniae. (= Eesti Teaduste Akadeemia Emakeele Seltsi toimetised nr 20 (67).) Tallinn. 
Westman, Margareta 1995. Språket och verkligheten. - Språkets lustgård och djungel. (= Skrifter utgivna av Svenska språknämnden 79.) Norstedts, 111-129.

Wiedemann, Ferdinand Johann 1973 (1893). Eesti-saksa sõnaraamat. Neljas, muutmata trükk teisest, Jakob Hurda redigeeritud väljaandest. Tallinn.

\section{Sõnavarakogud}

EMSUKA = Eesti murrete ja sugulaskeelte arhiiv Tallinnas Eesti Keele Instituudis. 


\title{
About one more violet blue
}

\author{
Meeli Sedrik
}

The stem variants panksee, pankse(-), panks(i)-, pank-, ponks(i)- 'certain blue, violet colour' have been recorded in the western dialect of Estonian, in the island dialect of the parishes on Hiiumaa and in Muhu and Kihelkonna parishes (according to the card catalogue of Estonian dialect words, held at the Institute of the Estonian Language in Tallinn, EMSUKA). This shade of colour was achieved by a dye bought from a shop and it was used for colouring yarn, fabric etc. The same word was used as a name for the dye itself as well.

The stem may have been borrowed from Swedish or German, Swedish pensé [panse:] 'pansy', German Pensée [pã'se:] 'pansy', pensée [pã'se:] 'dark violet'. Swedish and German sources fit both phonetically and semantically. There is no record of the Estonian dialectal stem as a plant name. Thus the stem is borrowed only as a colour word, probably as the name of a dye shade bought from a shop.

It is more likely that the stem in question is borrowed from German. There are other colour terms in Estonian dialects, e. g. neibla-, neiblusinine (German Neublau), ordjan, ordjon, ordenikollane (German Orlean(s)) which are German loanwords as well.

Keywords: Estonian dialects, language contacts, lexicology, etymology, loanwords

Meeli Sedrik

soome-ugri keelte ja murrete osakond

Eesti Keele Instituut

Roosikrantsi 6

10119 Tallinn

meelisedrik@hot.ee 